\title{
OPINIÓN DEL MAGISTERIO SOBRE EL TRABAJO SOCIAL EN PUERTO RICO ${ }^{1}$
}

\author{
Daritza Vélez Pérez ${ }^{2}$ \\ Irma Serrano-García ${ }^{3}$
}

\section{Resumen}

El trabajo social ocurre en varios escenarios y es capaz de producir opinión pública. Desde muy temprano en la historia de la profesión en Puerto Rico, los trabajadores y trabajadoras sociales se insertaron en las escuelas. El objetivo principal del presente estudio fue de conocer la opinión de un grupo de la Federación de Maestros de Puerto Rico sobre los trabajadores y las trabajadoras sociales. La muestra constó de 74 participantes cuya mayoría mostró una opinión positiva hacia los y las profesionales del trabajo social. El 35\% de la muestra no creía que estos y estas debían participar en procesos de política pública. Se encontró una relación directa entre la experiencia de maestros y maestras con profesionales del trabajo social y su opinión hacia estos y estas. Presentamos nuestro análisis y recomendaciones ante estos resultados.

Descriptores: Opinión, trabajo social, maestros y maestras, política pública

\begin{abstract}
Social work occurs in various settings and can generate public opinion. Early in the history of the profession in Puerto Rico, social workers began working in schools. The main objective of this study was to identify the opinion of a group of members of the Teachers' Federation of Puerto Rico about social workers. The sample consisted of 74 participants. The majority held a positive view toward social workers. Of the sample, $35 \%$ did not think social workers should participate in public policy processes. A direct relationship between their experience with social workers and their opinion towards them was found. An analysis of these results and our recommendations are included.
\end{abstract}

Key words: Opinion, social workers, teachers, public policy

\section{Introducción}

La profesión del trabajo social se estableció en Puerto Rico entre las décadas del 1920 y 1930 cuando comenzaron a surgir en la Isla agencias de bienestar social y programas federales de asistencia a la ciudadanía (Rivera de Alvarado, 1986; Ruiz, 2003). Hoy día, en Puerto Rico existen más de 6,000 trabajadores y trabajadoras sociales que se desempeñan en diferentes áreas y funciones. A pesar de la multiplicidad de roles que pueden asumir, esta profesión es, por

\footnotetext{
1 Este artículo está basado en la tesis de Daritza Vélez Pérez.

2 Estudiante graduada de psicología clínica de la Pontificia Universidad Católica de Puerto Rico.

3 Catedrática Jubilada del Departamento de Psicología, Universidad de Puerto Rico en Río Piedras.
} 
definición, una de ayuda con una función dual: por un lado actúa para mejorar el funcionamiento social de las personas y por otro interviene para enriquecer o ampliar las opciones que se le ofrecen a los individuos en su contexto (Ruiz, 2003). Entre las funciones más específicas del y de la profesional de trabajo social se encuentran: la intervención directa con individuos, grupos y comunidades; la investigación sobre el desarrollo y efecto de los diferentes problemas sociales; y el desarrollo de políticas sociales y planificación de iniciativas dirigidas al mejoramiento de la calidad de vida (Kisnerman, 1981).

Considerando el gran número de trabajadores y trabajadoras sociales que laboran en Puerto Rico, nos interesó conocer cuán aceptada es la profesión en el País y qué importancia se le adjudica. Varios autores y autoras han argumentado sobre la importancia que tiene para los y las profesionales de trabajo social conocer qué concepto tienen las otras personas hacia ellos y ellas y hacia la profesión. Según argumenta Ruiz, esa opinión pública es vital para definir y practicar la profesión: "[los] intentos de auto definición [del trabajo social] están influenciados directamente por el impacto que provocan ante la opinión pública aquellos [y aquellas] que la practican" (Ruiz, 2003, p. 15). En una línea similar de pensamiento, Kaufman y Raymond (1996, citado en Knežević y Butler, 2003) han señalado que la importancia de la opinión del público hacia el trabajo social radica en que el reconocimiento que recibe la profesión es esencial para su permanencia. Más concretamente, LeCroy y Stinson (2004) han identificado que la opinión del público es vital para la profesión porque: (a) si el público está confundido u hostil hacia la profesión, ésta no podrá cumplir con su misión de ayudar a las personas; (b) si la aprobación del público disminuye, los trabajadores y trabajadoras sociales perderán credibilidad frente a su clientela y demás profesionales y, por último, (c) la opinión del público es importante para que las personas se motiven a buscar servicios de trabajo social. De modo que le compete a la profesión conocer esa opinión pública para reflexionar sobre su quehacer profesional y tomar cursos de acción para mantener esa imagen o transformarla.

Desde la preocupación por hacer del trabajo social puertorriqueño una profesión que responda a los cambios sociales y económicos del país, así como a las necesidades de la población en general, se han suscitado al interior de la profesión reflexiones en torno a su práctica. Por ejemplo, Guardiola (1998) argumentó sobre la necesidad de que el trabajo social en Puerto Rico asuma una ideología que rompa con el asistencialismo que, según ella, ha caracterizado a la profesión. Respondiendo a esta preocupación es importante dar una mirada crítica a la imagen que ha proyectado la profesión. Esto implica un reto para cada trabajador y trabajadora social de verse a través de los ojos de otras personas, evaluar la profesión y a partir de ahí a reconstruir su imagen, de ser necesario. Así mismo, Rodríguez (1985) sostiene que:

Se hace necesario estudiar la proyección del trabajo social pues se ha señalado repetidamente que la imagen que proyecta el trabajo social es percibida por la comunidad como una de mantenimiento y control del orden social para beneficio del sistema. $\mathrm{Si}$ esta es la imagen que se proyecta y es la que la sociedad sanciona, cabe preguntarse si hay alguna posibilidad de que el trabajo social se convierta en una profesión generadora de cambios estructurales con la aceptación de la comunidad (Rodríguez, 1985, p.13).

Ante estos cuestionamientos, y dado que obtener la opinión del público general rebasaba nuestros recursos, decidimos enfocar este estudio en la opinión que tiene el magisterio de escuela pública 
en Puerto Rico sobre la profesión. Nos pareció un grupo idóneo para satisfacer nuestro interés, puesto que desde la década del 1930 los y las profesionales del trabajo social comenzaron a laborar junto a maestros y maestras en las escuelas, proveyéndoles así este escenario de vasta experiencia para generar una opinión sobre el trabajo social. Veamos a continuación un resumen breve del desarrollo histórico de la profesión, y de investigaciones previas que se han realizado para auscultar la percepción que de ella se tiene.

\section{Trasfondo Histórico de la Profesión}

En Puerto Rico el trabajo social comenzó a gestarse en la década del 1920. Se integraron trabajadoras sociales en el capítulo de la Cruz Roja Americana en Puerto Rico y en las unidades de salud pública. A estos grupos se le ofrecieron talleres de adiestramiento en la Universidad de Puerto Rico, bajo la iniciativa de Beatriz Lassalle. También se inició el trabajo social escolar en una escuela pública de la capital. Aunque este puesto en particular no surgió como iniciativa del gobierno, sino de la Asociación de Padres y Maestros de la escuela, el Departamento de Instrucción pública hizo una importante aportación al trabajo social al identificar la necesidad de servicios de bienestar social en las comunidades (Rivera de Alvarado, 1986). Se estableció, entonces, el programa de las Segundas Unidades Rurales acompañado de un programa de estudios de nueve créditos en la Universidad de Puerto Rico, ambos dirigidos por la trabajadora social estadounidense Dorothy D. Bourne (Burgos Ortiz, 1998).

Con las Segundas Unidades, el trabajo social se expandió desde la capital del País hacia diferentes pueblos de la Isla. Las personas a ocupar las plazas debían ser mujeres solteras y dispuestas a mudarse a los pueblos donde se estableciera el programa. Las funciones que tenían estas trabajadoras sociales eran muy variadas: intervenían con problemas de sanidad, fomentaban el trabajo en equipo, orientaban sobre la lactancia y alimentación de niños y niñas, visitaban hospitales y realizaban gestiones para conseguir los servicios que necesitaba la comunidad (Burgos Ortiz, 1998). El programa duró hasta el 1933, cuando la Administración Federal de Auxilio de Emergencia en Puerto Rico (PRERA, por sus siglas en inglés) comenzó a emplear estas trabajadoras sociales rurales para ocupar puestos de administración en esta agencia, mientras otras abandonaron los puestos por razones personales.

En el 1934 se creó la Junta Examinadora de Trabajo Social y se desarrollaron los requisitos para ejercer la profesión. De esta forma Puerto Rico se convirtió en el primer país de América en reglamentar la profesión del trabajo social. Poco después se fundó el Departamento Graduado de Trabajo Social y para el inicio de la década del 1940 se creó el actual Colegio de Trabajadores Sociales de Puerto Rico (CTSPR) (Burgos Ortiz, 1998; Rivera de Alvarado, 1986).

El trabajo social se estableció bajo una fuerte influencia estadounidense (Rodríguez, 1985; Ruiz, 2003), de modo que la iniciativa del trabajo social surgió del Estado y no del proletariado. Comenzó con un enfoque individualista, tomó un importante giro hacia un enfoque comunitario, pero luego se entronizó en las agencias gubernamentales. Para Rivera de Alvarado (1986), este último cambio representó un obstáculo para el desarrollo distintivo y autóctono del trabajo social puertorriqueño. 


\section{Trabajo Social Escolar}

A pesar de la desaparición del programa de las Segundas Unidades rurales, el trabajo social en las escuelas no desapareció. En años subsiguientes se nombraron profesionales de trabajo social con el fin de conocer el ambiente en que se desenvolvía el estudiantado después de las horas de clase (Rodríguez, 1985). Entre el 1956 y 1966 se extendió el programa al nivel secundario. En el 1986 una Carta Circular del Departamento de Instrucción Pública estableció las funciones de los y las profesionales del trabajo social escolar (Rodríguez, 1985). Algunas de éstas eran: identificar estudiantes cuyos problemas sociales o emocionales afectan su funcionamiento escolar; organizar grupos de estudiantes para guiarlos hacia una mayor responsabilidad social; ofrecer tratamiento social al estudiantado; ofrecer orientación a padres y madres sobre diversos aspectos de su prole; y ofrecer adiestramiento al personal escolar. Dos años después de esta carta circular, el Departamento de Instrucción especificó los requisitos del puesto de trabajo social escolar indicando que debía poseer licencia y pertenecer al CTSPR.

Más recientemente, en la Ley Orgánica para el Departamento de Educación de Puerto Rico, se establecieron las disposiciones legales del Programa de Trabajo Social Escolar, adscrito al Área de Servicios de Ayuda al Estudiante. En la Carta Circular Núm. 16 - 2004-2005 del Departamento de Educación se especificaron los objetivos de dicho programa así como las funciones del trabajo social escolar. El Programa persigue catorce (14) objetivos principales, que se resumen en facilitar, enriquecer, fortalecer y fomentar medios por los cuales el estudiantado y sus familias pueden resolver situaciones que afectan su ambiente y desarrollo social. De esta forma el campo de acción de estos y estas profesionales incluye tanto al estudiantado, como a su familia, la comunidad escolar y la comunidad en general. Además, se conceptualiza al o a la estudiante como un ser integral tomando en consideración aspectos bio-psico-sociales. Por otra parte, en la carta circular también se especificaron las funciones del trabajo social escolar, en un total de diecinueve (19), dirigidas a cuatro (4) áreas en particular: el estudiantado, los padres y madres, el personal escolar y el personal administrativo. Dichas funciones van dirigidas a la identificación de problemas e intervención, coordinación de actividades y servicios, investigación social, asesoramiento, orientación y consejería, establecimiento de grupos y talleres, colaboración con personal escolar y agencias, participación de reuniones administrativas y de discusión de casos y mantener informado al director o directora escolar sobre asuntos pertinentes, entre otras funciones relacionadas. El Programa de Trabajo Social Escolar, aunque es integral y organizado, es muy ambicioso y tal vez utópico, especialmente cuando consideramos que generalmente hay solo un trabajador o trabajadora social, en cada escuela, quien debe cumplir con todas las funciones y objetivos antes expuestos.

\section{Opinión sobre los Trabajadores y Trabajadoras Sociales y su Profesión}

De acuerdo a Ruiz (2003), la definición de la profesión está influenciada por la opinión pública que genera su práctica. En Estados Unidos y en Puerto Rico se pueden identificar varios esfuerzos dirigidos a examinar la opinión de las personas hacia los y las profesionales de trabajo social. En un estudio realizado con el propósito de conocer las actitudes de los maestros y maestras de educación especial sobre los y las profesionales de trabajo social escolar, se encontró que rechazaban la intervención de estos y estas profesionales por tener una imagen negativa de ellos y ellas. Consistentemente, el estudio demostró que a mayor desconocimiento por parte del magisterio sobre las funciones del trabajo social más negativa era la actitud hacia estos y estas profesionales 
(Tower, 2000). Por otra parte, un grupo de investigación administró un cuestionario para conocer la percepción del público hacia profesionales de psicología, psiquiatría, consejería y trabajo social. En los resultados, la profesión de trabajo social ocupó el último lugar de importancia (Fall, Levitov, Jennings, y Eberts, 2000).

Además de estos estudios, el Departamento de Salud de los Estados Unidos propulsó una investigación extensa para conocer las actitudes y la imagen del público hacia el trabajo social, la importancia que le adjudicaban a la profesión y el conocimiento sobre los requisitos para ejercerla. Entre los resultados obtenidos se destacaron confusión y desconocimiento sobre las tareas que realizan los y las profesionales del trabajo social y una imagen negativa hacia estos y estas, muy influenciada por la prensa. Sin embargo, las personas reconocían el trabajo social como una profesión importante, de mucha responsabilidad y demanda, pero mal pagada. Interesantemente, las personas entendían que la práctica del trabajo social requiere vocación y buenos sentimientos, más que una preparación académica (Department of Health, 2001).

En el 2004 se realizó otra investigación sobre la opinión hacia el trabajo social a nivel nacional en los Estados Unidos. Se escogió a las personas de manera aleatoria y se les entrevistó por teléfono. En el estudio se identificaron ideas estereotipadas de lo que hacen los trabajadores y trabajadoras sociales como, por ejemplo, solamente intervenir con personas pobres o remover menores de sus hogares. Pero, en general, los hallazgos apuntaron hacia una actitud favorable hacia la profesión y bastante conocimiento sobre sus funciones. Las personas identificaron asertivamente roles en la intervención de trabajo social como organización de comunidad, agente de cambio y terapeuta grupal y familiar (LeCroy y Stinson, 2004).

En Puerto Rico escasean las investigaciones y las que existen corresponden a tesis de maestrías realizadas en la década del 1980, con la excepción de una investigación realizada hace aproximadamente 10 años. En el 1985, Rodríguez analizó la percepción de un grupo de profesionales sobre el trabajo social. A pesar de que las personas le reconocían importancia a la profesión y describían los servicios entre "bueno" y "excelente", el $97 \%$ estuvo de acuerdo con que un área de competencia de los y las profesionales de trabajo social es proveer recursos materiales a la clientela. Esto representa más bien una idea estereotipada de la profesión y es consistente con lo expuesto por Guardiola (1998), quien describió la práctica del trabajo social como una asistencialista. Otro resultado importante es que el $60 \%$ que participó se mostró o en desacuerdo con el rol de trabajo social en la organización de protestas y piquetes y el 54\% indicó que los trabajadores y trabajadoras sociales no podían efectuar cambios sociales.

En 1988, en otra tesis de maestría, se exploró la opinión de los maestros y maestras de escuelas públicas sobre el Programa de Trabajo Social Escolar (David, et al,1988). La mayoría de las personas participantes reconoció correctamente las funciones del trabajo social escolar e indicaron que utilizaban los servicios para los problemas de ausentismo y mala conducta del estudiantado. Además, un $92 \%$ consideraba a los trabajadores y trabajadoras escolares como agentes de ayuda, pero el $66 \%$ consideró que los maestros y maestras podían realizar la labor de un profesional de trabajo social escolar.

En el 1997 se llevó a cabo una investigación con el objetivo de conocer la percepción de los legisladores y legisladoras de Puerto Rico sobre las funciones del trabajo social en el país. Se entrevistó un total de 37 participantes, la mayoría perteneciente a la Cámara de Representantes. 
Entre los hallazgos del estudio se encontró escaso conocimiento entre las personas participantes sobre las funciones de los y las profesionales de trabajo social. Pese a este desconocimiento clasificaron como deficiente la participación los trabajadores y trabajadoras sociales en política social. Además, se mostraron en desacuerdo con que estos y estas se involucraran en debates legislativos, vistas públicas y en evaluación de programas y servicios. Las autoras concluyeron que los y las profesionales de trabajo social no han dado a conocer de manera efectiva su función en la política social y que, por tanto, no se legitima su intervención en esta área (Guardiola y Serra, 1997). Este dato es consistente con los datos de Rodríguez (1985) de que sus participantes no consideraban que los trabajadores y trabajadoras sociales fuesen agentes de cambio social.

Por último, cabe mencionar las expresiones de Doris González (2006), pasada Presidenta del CTSPR. Según comentó, la sociedad puertorriqueña no reconoce el valor de la profesión de trabajo social. Las presiones económicas y políticas del País muchas veces limitan la labor de estos y estas profesionales y como consecuencia imperan ideas perjudiciales sobre la profesión. En resumen, los resultados de las investigaciones indican que la opinión hacia el trabajo social es variada, incluyendo aspectos negativos. Algunas explicaciones giran en torno a la falta de conocimiento sobre la profesión, y la posible influencia de la prensa. En Puerto Rico específicamente, encontramos pocas investigaciones y los tres estudios realizados - David et.al, 1988; Guardiola y Serra, 1997; Rodríguez, 1985 - reflejan que existe desconocimiento sobre algunas funciones de los trabajadores y trabajadoras sociales, poco reconocimiento a su labor e ideas estereotipadas. Es evidente que los trabajadores y trabajadoras sociales del País no se han ocupado lo suficiente por conocer la imagen que proyectan.

\section{Objetivos}

1. Conocer si un grupo de maestros y maestras había tenido experiencia con trabajadores y trabajadoras sociales.

2. Identificar si conocían las funciones de los trabajadores y trabajadoras sociales escolares.

3. Explorar la opinión de las personas participantes sobre las funciones que realizan los trabajadores y trabajadoras sociales.

4. Determinar si existía alguna relación entre la experiencia con los trabajadores y trabajadoras sociales escolares y la opinión hacia ellos y ellas.

\section{Hipótesis}

Los maestros y maestras que han tenido mayor experiencia con los trabajadores y trabajadoras sociales tendrán mejor opinión de la profesión.

\section{Método}

\section{Participantes}

El universo de los y las participantes lo constituyeron 290 maestros y maestras pertenecientes a las directivas de las 58 locales de la Federación de Maestros de Puerto Rico (Comunicación personal con Sra. Nereida Martes, Administradora de la FMPR, 11 de abril de 2007). La FMPR se define a si misma como un instrumento de lucha y solidaridad en pro de los derechos del magisterio y la educación (Federación de Maestros de Puerto Rico, 2010). Este grupo de maestros y maestras componen el liderato de la FMPR, lo cual les identifica como personas destacadas que 
pueden aportar información valiosa y cuya opinión puede influir en otros miembros del magisterio. Además, su participación nos permitió obtener datos de personas de diferentes pueblos de la Isla, ya que laboran en diferentes escuelas.

El universo de participantes fue contactado mediante correo regular y se les invitó a participar del estudio a través de cartas. Como se indica a continuación, se le incluyó en el envío la carta de la investigadora principal, una carta de la FMPR, una hoja de consentimiento recalcando la voluntariedad de su participación y la confidencialidad de la información y el cuestionario. Aquellas personas que quisieron participar devolvieron los instrumentos por correo separados de la hoja de consentimiento.

El total de participantes del estudio fueron 74 maestros y maestras. Su edad promedio fue de 49 años y el $51.4 \%(n=38)$ indicó pertenecer al género masculino. El $85.1 \%(n=63)$, nació en Puerto Rico y un $12.2 \%(\mathrm{n}=9)$ en Estados Unidos. La mayoría poseía un grado de bachillerato $(68.9 \%$, $\mathrm{n}=51$ ) completaron sus estudios en diferentes universidades del País. Así mismo, laboraban en diferentes áreas geográficas de la Isla (Véase Tabla 1).

\section{Tabla 1}

\section{Características Sociodemográficas de las Personas Participantes}

\begin{tabular}{ccc} 
Variable & $\mathrm{N}$ & $\%$ \\
\hline Género (N=74) & & \\
Femenino & 36 & 48.6 \\
Masculino & 38 & 51.4
\end{tabular}

Grado Académico $(\mathrm{N}=74)$

$\begin{array}{lll}\text { Bachillerato } & 51 & 68.9 \\ \text { Maestría } & 23 & 31.1\end{array}$

Institución donde obtuvo el grado $(\mathrm{N}=74)$

$\begin{array}{lll}\text { Universidad de Puerto Rico } & 24 & 32.4 \\ \text { Universidad Interamericana } & 20 & 27.0 \\ \text { Pontificia Universidad Católica } & 10 & 13.5 \\ \text { Caribbean University } & 4 & 5.4 \\ \text { Universidad del Turabo } & 3 & 4.1 \\ \text { Otras } & 13 & 17.5\end{array}$

Pueblo donde trabajaba $(\mathrm{N}=70)$

$\begin{array}{lll}\text { Área Central } & 21 & 30.0 \\ \text { Área Norte } & 17 & 24.2 \\ \text { Área Sur } & 13 & 18.5 \\ \text { Área Este } & 10 & 14.2 \\ \text { Área Oeste } & 9 & 12.8 \\ \text { No aplica (Retirado) } & 1 & 1.4\end{array}$




\section{Instrumentos}

Utilizamos una hoja de consentimiento, un cuestionario auto administrable de preguntas cerradas, una carta explicativa y una carta de la FMPR. En la hoja de consentimiento, aprobada por el Comité de Protección a los Sujetos Humanos en la Investigación (CIPSHI) de la Universidad de Puerto Rico (UPR), se encontraba información sobre el carácter voluntario de la participación, así como de la confidencialidad y los riesgos y beneficios de participar en el estudio. En la carta informativa le explicamos a los y las participantes el motivo del estudio y solicitamos su colaboración. Con su carta la FMPR apoyó la investigación y también solicitó la colaboración de sus miembros.

Desarrollamos el Cuestionario sobre la Opinión de los Maestros y Maestras (COM) teniendo como referencia el elaborado por Chévere, Serrano-García y Cabrera (2005) para auscultar la percepción sobre los psicólogos y psicólogas por parte de los miembros de la legislatura de Puerto Rico. El COM constó de tres secciones: (1) datos sociodemográficos, (2) experiencia de las personas participantes con los y las profesionales del trabajo social y (3) una escala Likert de cuatro puntos, desde "totalmente de acuerdo" hasta "totalmente en desacuerdo" para conocer la opinión de las personas participantes hacia los trabajadores y trabajadoras sociales.

\section{Procedimiento}

Luego de obtener el apoyo de la FMPR para realizar la investigación, solicitamos permiso del CIPSHI de la UPR, Recinto de Río Piedras. Con este endoso procedimos a realizar un estudio piloto para asegurar la claridad de la redacción de los reactivos y las instrucciones del instrumento.

El estudio piloto se realizó con dos maestras de escuelas públicas de Lares dada su disponibilidad y accesibilidad. La primera autora le administró los instrumentos y le indicó que le haría preguntas generales para que señalaran los reactivos que les generaron dudas. No hubo dudas en torno a los reactivos. Una participante recomendó añadir una premisa en la tercera sección.

Posterior al estudio piloto, la primera autora envió la carta explicativa y la de la FMPR, dos hojas de consentimiento, el COM y dos sobres predirigidos por correo regular al universo de personas participantes. Estas debían regresar una hoja de consentimiento firmada y el cuestionario utilizando los sobres predirigidos. Contestar dicho el cuestionario les debía tomar entre 5-10 minutos.

La FMPR proveyó, en etiquetas, las direcciones postales de todas las personas que integraban las directivas. El envío se realizó el 7 de mayo de 2007 desde la FMPR, de modo que no tuvimos acceso posterior a estas direcciones. Las respuestas se recibieron en la dirección postal de la primera autora. El último cuestionario se recibió el 10 de julio de 2007.

\section{Análisis}

Los datos se analizaron con el programa de computadora Statistical Package of Social Sciences (SPSS Versión 11.5). Realizamos análisis de estadísticas descriptivas y correlaciones entre la variable de experiencia y la de opinión. Además, se creó un índice para conocer la opinión que las personas participantes tenían sobre los trabajadores y trabajadoras sociales. Los totales obtenidos por cada participante en la escala Likert de la sección de opinión, se ubicaron en cuatro categorías 
que describían su opinión hacia los trabajadores y trabajadoras sociales: "muy positiva, "positiva", "negativa" y "muy negativa". El valor máximo posible era 60 , mientras el mínimo era 15. La primera categoría incluyó los valores desde el 60 al 49; la segunda del 48 al 37, la tercera del 36 al 25 y la última del 24 al 15.

\section{Resultados}

Todas las personas participantes del estudio indicaron haber tenido alguna experiencia con trabajadores y trabajadoras sociales. La experiencia más frecuente fue haber solicitado sus servicios para estudiantes $(97.3 \% ; n=72)$. Los resultados de la sección de opinión aparecen en la Tabla 2. Las aseveraciones con mayor puntuación en el indicativo de "totalmente de acuerdo" fueron las siguientes: "Los trabajadores/as son necesarios en Puerto Rico" y "Hacen falta más trabajadores/ as sociales escolares en Puerto Rico", ambas con un $81.1 \%(n=60)$ de respuestas. La puntuación más baja en ese mismo reglón, fue "En Puerto Rico se respeta a los trabajadores/as sociales" con un $14.9 \%,(n=11)$, aunque el $58.1 \%(n=43)$ de las respuestas de esa premisa correspondían al renglón "de acuerdo". Frecuencias similares obtuvo la premisa "Los trabajadores/as sociales son competentes", sólo un 25.7\% ( $\mathrm{n}=19)$ indicó estar "totalmente de acuerdo", pero el $58.1 \%(\mathrm{n}=43)$ se expresó "de acuerdo". Por otra parte, la premisa en la cual más personas se mostraron "totalmente en desacuerdo" fue: "Los trabajadores/as sociales deben involucrarse en procesos de política pública” con un $16.2 \%$, $(n=12)$ acompañado por un $18.9 \%$ "en desacuerdo".

Otros resultados relacionados a la opinión hacia los trabajadores y trabajadoras sociales fueron que un $55.4 \%(n=41)$ de las personas participantes estuvo "de acuerdo" con que estos y estas profesionales ejercen de manera responsable, seguido por un $29.1 \%(n=22)$ que estuvo "totalmente de acuerdo" con dicha afirmación. El $41.9 \%(n=31)$ estuvo "totalmente de acuerdo" con que los trabajadores y trabajadoras sociales son agentes de cambio social y un $50 \%(n=37)$ de los maestros y maestras estuvo "totalmente de acuerdo" con la afirmación de que los trabajadores y trabajadoras sociales aportan al bienestar del país.

En cuanto a premisas más relacionadas a conocimiento sobre las funciones de los trabajadores y trabajadoras sociales, observamos que en la afirmación de que los trabajadores y trabajadoras sociales se involucran en temas de familia, señalaron estar "totalmente de acuerdo" $51.4 \%(\mathrm{n}=38)$ de las personas. En la aseveración relacionada con que los trabajadores y trabajadoras sociales escolares intervienen con estudiantes con problemas académicos, estuvo "de acuerdo" un $44.6 \%$ $(n=33)$, seguido por un $27 \%(n=20)$ que expresó estar "en desacuerdo". En esa misma línea, la premisa relacionada a si los trabajadores y trabajadoras sociales intervienen con estudiantes de todas las clases sociales, el $50 \%(n=37)$ de los maestros y maestras expresó "total acuerdo". 
Tabla 2

Opinión de los Maestros y maestras sobre los Trabajadores y trabajadoras Sociales

\begin{tabular}{|c|c|c|c|c|}
\hline Premisa & $\begin{array}{l}\text { Totalmente } \\
\text { de acuerdo }(\%)\end{array}$ & $\begin{array}{c}\text { De acuerdo } \\
(\%)\end{array}$ & $\begin{array}{l}\text { En des- } \\
\text { acuerdo }(\%)\end{array}$ & $\begin{array}{l}\text { Totalmente en } \\
\text { desacuerdo }(\%)\end{array}$ \\
\hline
\end{tabular}

Los trabajadores/as sociales se $\quad 51.4$ involucran en temas de familia.

Los trabajadores/as sociales

29.1

40.5

8.1

0

ejercen su profesión de forma

responsable.

Los trabajadores/as sociales

81.1

55.4

12.2

son necesarios en Puerto Rico.

Los trabajadores/as sociales
escolares intervienen con

20.3

16.2

1.4

estudian-tes con problemas

académicos.

Los trabajadores/as sociales

son competentes.

Los trabajadores/as sociales

facilitan la solución de

problemas sociales.

Los trabajadores/as sociales

intervienen con estudiantes

50.0

33.8

14.9

de todas las clases sociales.

Los trabajadores/as sociales

deben involucrarse en procesos

de política pública.

Los trabajadores/as sociales $\quad 41.9$

son agentes de cambio social.

0

Hace falta más trabajadores/as
sociales escolares en Puerto Rico.

Los trabajadores/as sociales $\quad 50.0$

aportan al bienestar del país

En Puerto Rico se respeta a los 14.9

trabajadores/as sociales. en las escuelas.

Los resultados del índice de opinión aparecen en la Tabla 3. No hubo valores para la categoría de “muy negativa” ya que el valor mínimo registrado en el índice fue de 28. 
Tabla 3

Índice de Opinión sobre los Trabajadores y Trabajadoras Sociales

\begin{tabular}{lll} 
Categoría & $\mathrm{N}$ & $\%$ \\
\hline Muy positiva & 34 & 45.9 \\
Positiva & 36 & 48.6 \\
Negativa & 4 & 5.4 \\
\hline Total & $\mathbf{7 4}$ & $\mathbf{9 9 . 9 *}$
\end{tabular}

Total

74

\section{* No da cien por razones de redondeo}

Por último, exploramos la relación entre la experiencia de los maestros y maestras con los profesionales de trabajo social y la opinión hacia éstos y estas utilizando el coeficiente de correlación de Pearson. Hubo una correlación leve y positiva entre las dos variables $(r=.23, p=<.04)$ lo cual significa que a mayor experiencia con los trabajadores y trabajadoras sociales mejor era la opinión que los maestros y maestras tenían.

\section{Discusión}

La información obtenida de los datos sociodemográficos de las personas participantes contribuyó a fortalecer la investigación, ya que hubo una distribución equitativa por género y la muestra fue bastante heterogénea en cuanto a las universidades donde estudiaron y el pueblo donde trabajaban. Esta diversidad puede aumentar la posibilidad de variedad de experiencias con y opiniones sobre los trabajadores y trabajadoras sociales.

En nuestra opinión, ya que la totalidad de las personas participantes señalaron que habían tenido alguna experiencia con profesionales del trabajo social, podemos pensar que sus opiniones estaban influenciadas por sus experiencias y no necesariamente por estereotipos sobre la profesión. Además, al indicar que habían solicitado los servicios de trabajo social para su estudiantado, confirmamos que los trabajadores y trabajadoras sociales son necesarios en las escuelas Más aún, parece ser que su labor es insuficiente para la demanda de servicios, pues la mayoría de los maestros y maestras pensaba que en nuestro País hacen falta más trabajadores y trabajadoras sociales escolares.

En general, los maestros y maestras participantes tenían una opinión positiva hacia los trabajadores y trabajadoras sociales. La mayoría pensaba que los y las profesionales del trabajo social aportan al bienestar del país, que son agentes de cambio social y que son competentes. Aportar al bienestar social es una función de la profesión, que va dirigida a la erradicación de los diferentes problemas sociales del país. Está ligada al concepto de agente de cambio, puesto que el trabajador y la trabajadora social intervienen para lograr cambios positivos tanto a nivel individual como grupal y social, con el propósito de mejorar la calidad de vida. Este rol también fue uno de los que fueron asertivamente indicados por quienes participaron en el estudio de LeCroy y Stinson (2004). Por otra parte, podemos afirmar que los trabajadores y trabajadoras sociales adquieren conocimientos y destrezas en su educación que les hacen competentes para intervenir en diferentes situaciones. Estas declaraciones de las personas participantes son bien importantes 
para la profesión en Puerto Rico, especialmente al contrastarlas con otras investigaciones fuera del país que señalan el poco valor que se le adjudica al trabajo social.

A tenor con lo anterior, la mayoría de los maestros y maestras se mostró "de acuerdo" y "totalmente de acuerdo" con la premisa de que los trabajadores y trabajadoras sociales ejercen su profesión de manera responsable. Podemos pensar, que es así. Desde muy temprano en la formación de la profesión de trabajo social en Puerto Rico, se estableció un Código de Ética (CTSPR, 1982). El mismo contiene guías para el comportamiento profesional de quienes ejercen la profesión. Sin embargo, nos parece que lo más importante de este dato es comentar lo favorable que resulta el mismo como insumo para una profesión que interviene con situaciones que podemos describir como controversiales, como la remoción de menores de sus hogares, la intervención en la violencia doméstica, intentos de suicidios, entre otras. Este dato, además, contrasta con las imágenes negativas presentadas en los medios de comunicación sobre intervenciones de profesionales del trabajo social, las cuales se pueden concebir como hechos aislados.

Otras reacciones que se deben examinar fueron las obtenidas en la premisa "En Puerto Rico se respeta a los trabajadores/as sociales". Un grupo mayor se expresó de acuerdo con la misma, seguido por otro grupo que se expresó en desacuerdo. Es decir, que la mayoría de los maestros y maestras cree que muchas personas del país sí respetan a los trabajadores y trabajadoras sociales, mientras otro grupo de participantes, aunque menor, piensa que son pocas las personas en Puerto Rico que les respetan. La opinión del grupo mayoritario puede deberse a que los trabajadores y trabajadoras sociales se han ganado este respeto por medio de la labor que realizan. Para comprender la respuesta del otro grupo, debemos tomar en cuenta, primeramente, que éste forma parte de toda la muestra, cuya opinión general hacia los trabajadores y trabajadoras sociales es positiva. De modo que tal vez estas personas sí respetan a los y las profesionales del trabajo social, pero piensan que otras personas no. Esto es cónsono con los hallazgos de otras investigaciones que indican que hay una opinión negativa general hacia los trabajadores y trabajadoras sociales, mayormente difundida por los medios de comunicación (Department of Health, 2001; Tower, 2000).

Por otra parte, la mayoría de los maestros y maestras mostró acuerdo con que los y las profesionales del trabajo social escolar intervienen con estudiantes con problemas académicos. Hay que tomar en cuenta, sin embargo, que la cantidad de personas que se mostraron "en desacuerdo" con la premisa, fue mayor que la cantidad de personas que se mostraron "totalmente de acuerdo". La discrepancia en las respuestas a esta premisa puede deberse principalmente a dos razones. La primera sería el desconocimiento de que algunas funciones del trabajador y la trabajadora social escolar van dirigidas a identificar razones por las cuales el estudiantado tiene problemas de aprovechamiento académico. La otra explicación es que los maestros y maestras piensen que los trabajadores y trabajadoras sociales escolares atienden más bien otro tipo de situaciones como podrían ser problemas de conducta, grupos de interés en las escuelas, entre otros. Ahora bien, los maestros y maestras también contestaron afirmativamente que los trabajadores y trabajadoras sociales intervienen con estudiantes de todas las clases sociales. Esto es positivo para la profesión porque nos lleva a pensar que el mito de que los trabajadores y trabajadoras sociales trabajan sólo con poblaciones pobres y marginadas no está arraigado en este grupo del magisterio del país.

Las personas participantes reconocieron que los y las profesionales del trabajo social intervienen en temas de familia, es decir, saben que el trabajo social no se limita a la intervención individual. 
La familia es uno de los escenarios de acción del trabajo social como profesión (Ander-Egg 1995; Kisnerman, 1981). Sin embargo, parece ser que su visión sobre el radio de intervención del trabajo social no es tan amplia como quisiéramos, puesto que en lo relacionado a la participación de los trabajadores y trabajadoras sociales en política pública, un número considerable se mostró en total desacuerdo o desacuerdo. Podemos pensar en varias explicaciones para este resultado. Una de éstas es que exista un nivel de desconocimiento entre las personas participantes sobre la legitimidad de la política pública como área legítima de intervención, según se estipula en la literatura. La otra vertiente es que los maestros y maestras sientan apatía hacia la intervención del trabajo social en la política. Esto no podemos constatarlo, pero de ser cierto sería bastante sorprendente, ya que se trata de miembros de la Junta Directiva de FMPR, una organización que se ha distinguido por su lucha con varias instancias del gobierno de Puerto Rico. Por otra parte, también hay que mencionar que este es un tema de discusión actual en la profesión de trabajo social. Aunque la política pública está legitimada como área de intervención, la participación en la misma por parte de trabajadores y trabajadoras sociales en Puerto Rico es baja (Canino, Lugo, Díaz, Vélez, Carvallo y Serrano-García, 2008). Por último, dicho hallazgo es afín con los resultados de Guardiola y Serra (1997) en los cuales los legisladores y legisladoras mostraron desacuerdo con que los y las profesionales del trabajo social participaran en debates legislativos y vistas públicas.

Otro dato que hay que recalcar es la afirmación por parte de los maestros y maestras de que los trabajadores y trabajadoras sociales son necesarios en nuestro País. Este dato, al igual que otros mencionados, confirma la importancia de la presencia de la profesión de trabajo social en Puerto Rico. Tales resultados contrastan con lo sugerido por la Presidenta del CTSPR, quien expresó que en Puerto Rico existe legitimación limitada e ideas negativas sobre la profesión (González, 2006). Sin embargo, estas posturas y los hallazgos del presente estudio no son del todo contrarias, sino que podemos afirmar que en medio de matices negativos hacia la profesión, existe una opinión y una valoración positiva de la labor de trabajadores y trabajadoras sociales de Puerto Rico y sus aportaciones al bienestar social del País. De hecho, resulta muy interesante que en los resultados del índice de opinión ninguna de las personas participantes demostró tener una opinión muy negativa hacia la profesión y sólo cuatro de estas coincidieron en una opinión negativa. De modo que la gran mayoría demostró tener una opinión "positiva" y "muy positiva" sobre los trabajadores y trabajadoras sociales en nuestro país.

Por último, se comprobó la hipótesis propuesta para esta investigación, ya que vimos que a mayor experiencia con los y las profesionales del trabajo social más positiva es la opinión hacia estos y estas. Aunque la correlación resultó moderada, sí es significativa, específicamente al considerar que el tamaño de la muestra es modesto. Este resultado podría sugerir que las expresiones negativas sobre la profesión surgen de la falta de contacto con trabajadores y trabajadoras sociales, o de la imagen creada en los medios, y no necesariamente de acciones negativas ejecutadas por estos y estas profesionales.

En resumen, podemos concluir que este grupo de maestros y maestras, partiendo de sus experiencias con los trabajadores y trabajadoras sociales, tiene una imagen positiva hacia la profesión. Nos quedaría preguntarnos si esta es la opinión generalizada del magisterio del país. 


\section{Recomendaciones}

No queremos terminar este trabajo sin incluir algunas recomendaciones. Pensamos que una primera intervención sería continuar diseminando estos resultados en diversos foros. Como ya hemos indicado la opinión que exista de la profesión contribuirá a su definición y transformación. Saber que un grupo del magisterio entiende que la labor de los trabajadores y trabajadoras sociales escolares es positiva puede proveer sostén y estímulo para quienes la realizan.

Recomendamos además, que la profesión de trabajo social genere formas de contrarrestar las imágenes negativas que puedan existir de la profesión. Esto puede ser tarea de algún grupo de trabajo del Colegio de Trabajadores Sociales de P.R.

Por otra parte, los trabajadores y trabajadoras sociales también deben orientar a los maestros y maestras sobre la amplia gama de funciones que pueden ejercer en el escenario escolar, con el fin de minimizar el desconocimiento de algunas sus funciones, como vimos en los resultados. También se recomienda aumentar el número de trabajadores y trabajadoras sociales en las escuelas, como opinaron los participantes, ya que dada su escasez no pueden suplir la demanda de servicios y las múltiples funciones que se les requieren.

En cuanto al número considerable de maestros y maestras que se mostró en desacuerdo con la participación de los y las profesionales del trabajo social en política pública, se recomienda que el CSTPR de a conocer la legitimidad de esta área de intervención mediante su participación activa en la misma. El CSTPR podría crear alianzas con otras organizaciones profesionales que se desempeñan en ese nivel de intervención incluyendo entre estas a la Asociación de Psicología de Puerto Rico. También recomendamos que este renglón se fortalezca en la preparación académica de estos y estas profesionales.

Por último, recomendamos explorar la opinión de integrantes de la Asociación de Maestros de Puerto Rico para tener un perfil más completo de la opinión de sus integrantes y comparar resultados. De igual forma, se debe investigar la opinión de otros sectores de la sociedad en torno al trabajo social.

En conclusión, este atisbo a la percepción que del trabajo social tiene este grupo de maestros y maestras debe ser aliciente para continuar el trabajo esmerado en las escuelas y para fortalecer a través de diversos medios el alcance de la intervención del trabajo social en nuestra sociedad. 


\section{Referencias}

Ander-Egg, Ezequiel. (1995). Diccionario de trabajo social. Buenos Aires, Argentina: Lumen

Burgos Ortiz, Nilsa M. (1998). Pioneras de la profesión de trabajo social. Hato Rey, Puerto Rico: Publicaciones Puertorriqueñas.

Canino, María, Lugo Hernández, Eduardo, Díaz Meléndez, Lymari, Vélez Pérez, Daritza, Carvallo Messa, Verónica y Serrano-García, Irma (2008). Encuesta de la participación de trabajadoras y trabajadores sociales en la política pública de Puerto Rico. Política Social y Trabajo Social, Serie Atlantea, 4, 67-87.

Chévere, Karisol, Serrano-García Irma y Cabrera, María del Carmen. (2005). Legisladores/as y asesores/as- Percepción de la participación de los/as psicólogos en política pública. Río Piedras. Departamento de Psicología, Universidad de Puerto Rico.

Colegio de Trabajadores Sociales de Puerto Rico (1982). Código de ética del trabajador social de Puerto Rico. San Juan, Puerto Rico: Autor.

David, Francisca, Flores, José, Moreno, Iris, Pagan, Elba, Pérez, Edith, Velazco, Marta, et al. (1988). La visión del maestro de salón de clases sobre el Programa de Trabajo Social en los distritos escolares de Aguada, Añasco, Guánica, Guayanilla, Isabela, Jayuya, Rincón y Santa Isabel. Tesis de maestría en trabajo social no publicada. Universidad de Puerto Rico, Río Piedras.

DepartamentodeEducación.(2004).CartaCircularNúm.16-2004-2005.SanJuan,PuertoRico:Autor

Department of Health. (2001). Perceptions of social work and social care: Report of findings. Accedido en http://www.dh.gov.uk/assetRoot/04/07/43/21/04074321.pdf

Fall, Kevin, Levitov, Justin, Jennings, Maureen y Eberts, Stephanie (2000). The public perception of mental health professions: An empirical examination. Journal of Mental Health Counseling, 22 (2), 122- 134.

Federación de Maestros de Puerto Rico. (s.f.). Constitución y Reglamento de la Federación de Maestros de Puerto Rico, San Juan, P.R.: Autor.

Federación de Maestros de Puerto Rico. (2010). Opúsculo de servicios y beneficios a los afilia-dos de la FMPR. Accedido en http://www.fmprlucha.org/sites/default/files/Opus\%20 AFILIATE\% 202010.pdf

González, Doris (2006, 30 de octubre). De lo invisible a lo visible. El Nuevo Día, p.72.

Guardiola,Dagmar.(1998).TrabajosocialenPuertoRico: ¿Asistencia,desarrollootransformación? Río Piedras. P.R.: Edil. 
Guardiola, Dagmar. y Serra, Juan. (1997). El trabajo social y los legisladores como formuladores de política social en Puerto Rico. Documento Inédito. Escuela Graduada de Trabajo Social Beatriz Lasalle Universidad de Puerto Rico, Río Piedras.

Kisnerman, Natalio. (1981). Colección teoría y práctica del trabajo social. [Volumen1] Buenos Aires, Argentina: Hvmanitas.

Knežević, Mladen y Butler, Lauren(2003). Public perception of social work in the Republic of Croatia. International Journal of Social Welfare, 12 (1), 50 - 60.

LeCroy, Craig y Stinson, Erika (2004). The public's perception of social work: Is it what we think it is? Social Work, 49 (2), 164-174.

Rodríguez, Ursula. (1985). Trabajo social en Puerto Rico: Opinión que tienen otros profesionales del área metropolitana de San Juan sobre el trabajo social en Puerto Rico. Tesis de maestría no publicada, Universidad de Puerto Rico, Río Piedras.

Rivera de Alvarado, Carmen. (1986). Lucha y visión de Puerto Rico libre. Río Piedras, Puerto Rico: Fundación Carmen Rivera de Alvarado y Antonio Alvarado.

Ruiz, Magali. (2003). La práctica del trabajo social: De lo específico a lo genérico. Río Piedras, PR: Editorial Edil.

Tower, Kristine. (2000). Image crisis: A study of attitudes about school social workers. Social Work in Education, 22 (2), 83- 94. 